\title{
Structural properties of cellulose nanofibril foam depending on wet foaming conditions in Pickering stabilization
}

\author{
Shin Young Park $\cdot$ Sooim Goo $\cdot$ Heenae Shin $\cdot$ Jinseung Kim $\cdot$ Hye Jung Youn $\mathbb{C}$
}

Received: 30 May 2021/Accepted: 15 August 2021/Published online: 8 September 2021

(C) The Author(s) 2021

\begin{abstract}
Porous cellulose nanofibril (CNF) foam was prepared by stabilizing bubbles with CNF and a surfactant and then drying the stabilized wet foam in a convection oven. The consistency of carboxymethylated CNF (CMCNF) and the addition amount of the surfactant were controlled and the effects of these factors on the CNF wet foam and dry foam properties were investigated. An adequate amount of the surfactant (0.02-0.04 wt\%) with CMCNF consistency higher than $0.5 \mathrm{wt} \%$ yielded wet foams with excellent stability. When the wet foam was dried at $60{ }^{\circ} \mathrm{C}$ in an oven, dry CNF foam with over $97 \%$ porosity was generated. The stable wet foams resulted in dry CNF
\end{abstract}

Supplementary Information The online version contains supplementary material available at https://doi.org/10.1007/ s10570-021-04151-8.

\section{S. Y. Park}

Department of Forest Sciences, College of Agriculture and Life Sciences, Seoul National University, 1 Gwanakro, Gwanak-gu, Seoul 08826, Korea

S. Goo · J. Kim $\cdot$ H. J. Youn $(\bowtie)$

Department of Agriculture, Forestry and Bioresources, College of Agriculture and Life Sciences, Seoul National University, 1 Gwanak-ro, Gwanak-gu, Seoul 08826,

Korea

e-mail: page94@snu.ac.kr

H. Shin · H. J. Youn

Research Institute of Agriculture and Life Sciences, Seoul National University, 1 Gwanak-ro, Gwanak-gu,

Seoul 08826, Korea foam with a sphere-like pore structure and low levels of shrinkage during drying. In contrast, unstable wet foams generated dry foam with severe shrinkage and large cavities. The pore size and the porosity of the dried foam were determined by the shape of bubbles in the wet foam and the degree of shrinkage during drying, which, in turn, affected the mechanical strength. In addition, the compressive strength of the oven-dried foam was $83 \%$ higher than that of the freeze-dried foam. Therefore, the preparation of a stable wet porous CMCNF foam by controlling the CMCNF consistency and the amount of surfactant was essential for obtaining a porous CMCNF foam with a uniform pore structure and good mechanical strength by oven drying.

\footnotetext{
H. J. Youn

State Key Laboratory of Biobased Material and Green Papermaking, Qilu University of Technology, Shandong Province, Shandong Academy of Sciences, Jinan 250353, People's Republic of China
} 


\section{Graphic abstract}
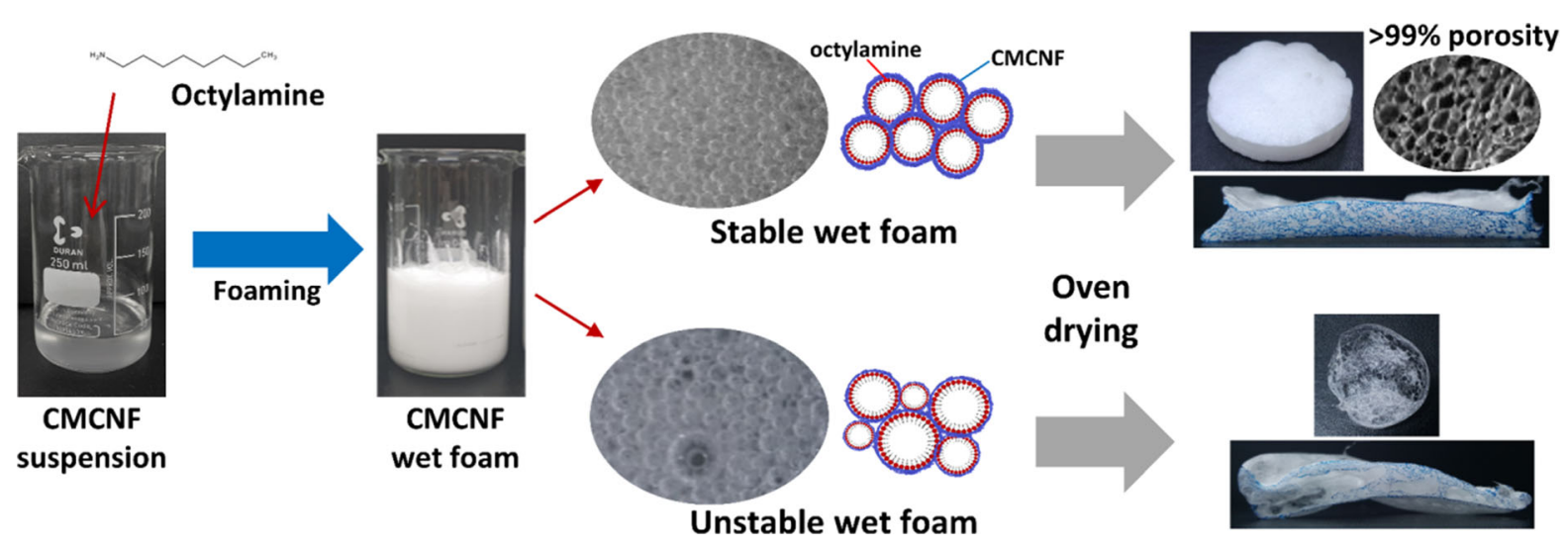

Keywords Cellulose nanofibril · Foam · Oven drying · Pickering stabilization · Structural stability

\section{Introduction}

Porous materials, such as foams and aerogels, have low densities and high porosities. Depending on the structure and size distribution of the pores, foams and aerogels can be applied to many fields including packaging (Chen et al. 2020; Manzocco et al. 2021), thermal insulation (Hasan et al. 2017; Illera et al. 2018), adsorbents (Hong et al. 2018; Singh et al. 2018; Bolisetty et al. 2019), and energy storage (Liu and Chen 2014; Huang et al. 2019). However, most of these materials are manufactured from petroleum chemicals or silica, which exhibit poor sustainability and biodegradability or high brittleness (Demilecamps et al. 2015; Feng et al. 2015; Gupta et al. 2018). Therefore, the demand for environmentally friendly porous materials has increased.

Cellulose, which is extracted mainly from plants, is an abundant, renewable, and biodegradable polymer. Cellulose nanofibril (CNF) is one of cellulose nanomaterials with a high aspect ratio and unique properties such as high mechanical strength and low density. In addition, CNF can be either processed into various forms (including hydrogels, sheets, and porous materials) or used as a reinforcing element for composites (Dufresne 2013, 2017; Kim et al. 2015b; Abitbol et al. 2016).
When a CNF suspension is dried via freeze drying or supercritical drying, water is eliminated from the suspension and air can fill the spaces resulting from this elimination (Heath and Thielemans 2010; Sehaqui et al. 2010; Martoïa et al. 2016). Using these methods, CNF can be processed into eco-friendly porous materials. CNF-based porous material exhibiting performance comparable to that of existing porous materials can be used as a substitute for petroleumbased foams or aerogels. The material can then be used in packaging (de Oliveira et al. 2019), adsorbent (Zhang et al. 2016; Li et al. 2018), insulation (Gupta et al. 2018), flame retardant (Ghanadpour et al. 2015; Köklükaya et al. 2017), and energy storage (Du et al. 2017) applications. Several studies have reported the production of CNF-based porous materials through freeze drying or carbon dioxide supercritical drying (Jin et al. 2004; Pääkkö et al. 2008; Kim et al. 2015a; Darpentigny et al. 2020). However, these methods are time-consuming and costly.

Recently, an alternative process based on Pickering stabilization has been introduced for the production of CNF-based foams. This stabilization refers to a process where the interfaces between two phases are stabilized with solid particles (Pickering 1907; Binks 2002). Many types of particles such as silica, clay, starch, protein, or chitosan have been used for the stabilization process, and the stabilization effect is different depending on the morphology and characteristics of the particles (Yang et al. 2017). In addition, CNF with a high aspect ratio can be used to stabilize the interfaces between two phases (Xhanari et al. 2011). 
The stabilization ability of CNF has usually been applied to the preparation of oil-in-water $(\mathrm{o} / \mathrm{w})$ emulsions and the stabilization of air-water interfaces (Guevara et al. 2013). Bubbles usually undergo coalescence, coarsening, and Ostwald ripening, and are eventually destroyed. However, CNFs accumulated on the air-water interfaces of bubbles can prevent this destruction, thereby increasing the stability and lifetime of the bubbles (Huang et al. 2018; Tenhunen et al. 2018; Xiang et al. 2019).

Using the Pickering stabilization concept, Cervin et al. (2013) prepared porous CNF foams with a porosity of $98 \%$. This was achieved through simple oven drying of a CNF wet foam after stabilizing airwater interfaces with $\mathrm{CNF}$ and the cationic surfactant, octylamine. They also investigated the mechanism of stabilizing effect of CNFs in wet foams and found that a high aspect ratio of $\mathrm{CNF}$, an increase in the concentration of $\mathrm{CNF}$, and an increase in the charge density of CNF could increase the complex viscoelastic modulus of the CNF-accumulated air-water interfaces (Cervin et al. 2015). In addition, high-stability foams were prepared by reinforcing the foam walls by calcium ion-induced aggregation (Gordeyeva et al. 2016) or crosslinking the CNF by introducing aldehyde (Cervin et al. 2016). An increase in humidity during drying can reduce the drying speed and prevent the shrinkage of the foam and the formation of cavities (Cervin et al. 2016). Nevertheless, studies on the production of $\mathrm{CNF}$ foams via Pickering stabilization are rare compared with those on freeze-dried CNF materials. The effect of various factors on the characteristics of CNF foam remains unclear.

Wet foaming conditions such as the foaming degree, bubble size, and foaming stability are essential for preparing porous CNF foam with a uniform structure and controlling the foam structure. The structure can be affected by the CNF consistency and surfactant amount. Therefore, the aim of this study was to investigate the effects of CNF suspension consistency and the surfactant amount on the characteristics of Pickering-stabilized CNF wet and dry foams. CNF wet foam with various foaming conditions was prepared and the characteristics of the wet foam were evaluated. In addition, the foams were dried in an oven, and the drying behavior and porous structure of each dried foam were investigated. Furthermore, the relationship between the properties of the wet foam and the dried foam was examined.
Through this study, we tried to suggest the optimal conditions for the production of oven-dried CNF foam and a way to control the characteristics of the CNF foam.

\section{Materials and methods}

\section{Materials}

Cellulose nanofibrils were prepared from hardwood bleached kraft pulp (HwBKP, Moorim P\&P, Korea). Chloroacetic acid (Sigma Aldrich, USA), sodium hydroxide (Samchun Chemicals Co. Ltd., Korea), and isopropanol (Samchun Chemicals Co. Ltd., Korea) were used for carboxymethylation pretreatment of the pulp fibers. Octylamine (OA, Sigma Aldrich, USA) was used as a cationic surfactant to prepare wet foam.

\section{Preparation of carboxymethylated CNF (CMCNF)}

Prior to grinding, the pulp was carboxymethylated using a method described in a previous study (Im et al. 2018) to obtain CNF with a more uniform fibril size. Sodium hydroxide $(\mathrm{NaOH} ; 4 \mathrm{mmol} / \mathrm{g}$ pulp) was dissolved in isopropanol. The pulp was added to the $\mathrm{NaOH} /$ isopropanol solution, and then reacted at $35{ }^{\circ} \mathrm{C}$ for $30 \mathrm{~min}$. Chloroacetic acid ( $1.5 \mathrm{mmol} / \mathrm{g}$ pulp) was added to the suspension and then reacted at $65^{\circ} \mathrm{C}$ for $1 \mathrm{~h}$. After the reaction, the reacted pulp was washed repeatedly with deionized water. The carboxyl group content of the reacted pulp was determined using a conductometric titration method in accordance with SCAN-CM 65:02. Carboxymethylated cellulose nanofibril (CMCNF) was prepared by grinding the pretreated pulp suspension (1.0 wt $\%$ ) 10 times using a grinder (Supermasscolloider, Masuko Sangyo, Japan). The carboxyl group content of the prepared CMCNF (average width: $5.2 \mathrm{~nm}$ ) was $870 \mu \mathrm{mol} / \mathrm{g}$.

Foaming of CMCNF-stabilized wet foam

CMCNF suspensions with different levels of consistency $(0.25-1.0 \mathrm{wt} \%)$ were prepared. Octylamine was added to $50 \mathrm{~g} \mathrm{CMCNF}$ suspension by $0.01-0.06 \mathrm{wt} \%$ based on the weight of the suspension. The suspension was then vigorously stirred for $5 \mathrm{~min}$ with an overhead stirrer. The original volume of the suspension $\left(V_{i}\right)$ and the volume of the wet foam immediately after the 
foaming $\left(V_{f}\right)$ were measured. Using these two volumes, the foamability, i.e., the ratio of volume increase induced by foaming, was calculated as follows:

Foamability $(\%)=\frac{V_{f}}{V_{i}} \times 100$

The average foamability of the wet foam was calculated from the three measurement values.

\section{Characterization of surfactant-added CMCNF} suspension

The zeta potentials of the CMCNF suspensions with different octylamine contents were measured to evaluate the effect of the addition of a cationic surfactant on the charge of the CMCNF. $0.1 \mathrm{wt} \% \mathrm{CMCNF}$ suspensions were prepared with the addition of $0-12 \mathrm{wt} \%$ octylamine based on the CMCNF oven-dried weight. The suspensions were gently mixed to avoid generating bubbles. The measurements were conducted using a Zetasizer nano (ZEN3600, Malvern Panalytical Ltd., UK) with a disposable folded capillary cell (DTS1070).

\section{Characterization of CMCNF-stabilized wet foam}

$1 \mathrm{~mL}$ of each wet foam was transferred onto the glass slide and observed for $6 \mathrm{~h}$ using an optical microscope (Sometech, Korea). From images of the bubbles in each foam, the average diameter of these bubbles was obtained by measuring the diameter of more than 100 bubbles using the Image J program. To assess the longterm stability of the foams, each was placed in a $20-\mathrm{mL}$ vial after foaming, and the change in the appearance of the foam was observed for 7 days.

The oscillatory rheological property of the wet foam was measured using a Bohlin CVO Rheometer (Malvern Panalytical Ltd., UK) with cone-plate geometry ( $4^{\circ}$ angle, $40 \mathrm{~mm}$ diameter) and $300 \mu \mathrm{m}$ gap size. The storage modulus and loss modulus of each foam were measured for shear stress values ranging from 0.1 to $1000 \mathrm{~Pa}$ under an amplitude sweep mode at $1 \mathrm{~Hz}$ frequency. In addition, the yield stress was determined as the stress value that intersects two tangential lines of the viscoelastic region and flow region of the storage modulus curve. The average yield stress was obtained from three measurements.
Drying and characterization of dry foam

A portion (20 g) of each wet foam was poured into a 55-mm-diameter polytetrafluoroethylene (PTFE) dish. Each foam was heated at $60{ }^{\circ} \mathrm{C}$ in an oven until they were completely dried. The pore structure of the foams was observed via field-emission scanning electron microscopy (FE-SEM; SUPRA 55VP, Carl Zeiss, Germany). Prior to observation, the dried foam was cut into cubes using a razor blade, and the crosssection of each specimen was coated with Pt (thickness: $10 \mathrm{~nm}$ ). Using the Image $\mathrm{J}$ software, the average pore size and the average pore-wall thickness were determined from the SEM images.

The apparent density, porosity, and shrinkage ratio in the thickness direction of the foam during drying were measured. The density of the foam was determined by weighing the $1 \mathrm{~cm}^{3}$-cubic foam. At least five cubic foams were tested for determination of the density of the dry foam. Furthermore, the porosity $(\emptyset)$ was determined using Eq. (2).

$\emptyset(\%)=\left(1-\frac{\rho}{\rho_{c}}\right) \times 100$

where, $\rho$ is the density of the dried foam and $\rho_{c}$ is the density of the cellulose $\left(1500 \mathrm{~kg} / \mathrm{m}^{3}\right)$. The shrinkage ratio in the thickness direction of the foam was calculated by measuring the thickness of the foam before and after drying.

The dry foam was subjected to compression tests conducted on a Universal Testing Machine (Instron 5943, Instron, USA). The foam was cut into $1 \times 1 \mathrm{~cm}$ cubic specimens and conditioned at $23{ }^{\circ} \mathrm{C}, 50 \% \mathrm{RH}$ for a day. A compression strain that was set to $90 \%$ of the foam height and a compression speed of $10 \mathrm{~mm} / \mathrm{min}$ were employed. More than four specimens were tested for each condition. The compressive strength of the foam was determined as the stress value at $80 \%$ strain. Moreover, the energy absorption of the foam was determined by calculating the area below the strainstress curves (for strains ranging from 0 to $80 \%$ ). 


\section{Results and discussion}

\section{Characteristics of CNF wet foam}

The effect of the CNF consistency and the amount of octylamine on the wet foam generation was investigated in terms of foamability, bubble morphology, and rheology. The volume of the octylamine-added CMCNF suspension increased due to the generation of bubbles during vigorous stirring of the suspension. In addition, the foamability of the wet foam, which indicates the ratio of the volume before and after foaming, was determined (Fig. 1). The increased volume after foaming was originated from the entrained air by stirring. The foamability of the CNF suspension with low consistency was relatively high. The foamability of the $0.25 \mathrm{wt} \%$ CNF suspension was $>200 \%$ for all surfactant amounts, indicating that the volume of the suspension increased two-fold relative to the volume before foaming and increased slightly with increasing surfactant dosage. Because the viscosity of the CMCNF suspension was low (96 cPs), bubbles were greatly generated at low surfactant dosages by vigorous stirring, but there may have been a limit to the foamability. In the case of the $0.5 \mathrm{wt} \%$ suspension, the foamability was less than $125 \%$ at $0.01 \mathrm{wt} \%$ octylamine content, which was likely owing to the increased viscosity of the CNF suspension (960 cPs) compared with the $0.25 \mathrm{wt} \% \mathrm{CNF}$ consistency. However, when the octylamine content increased, the

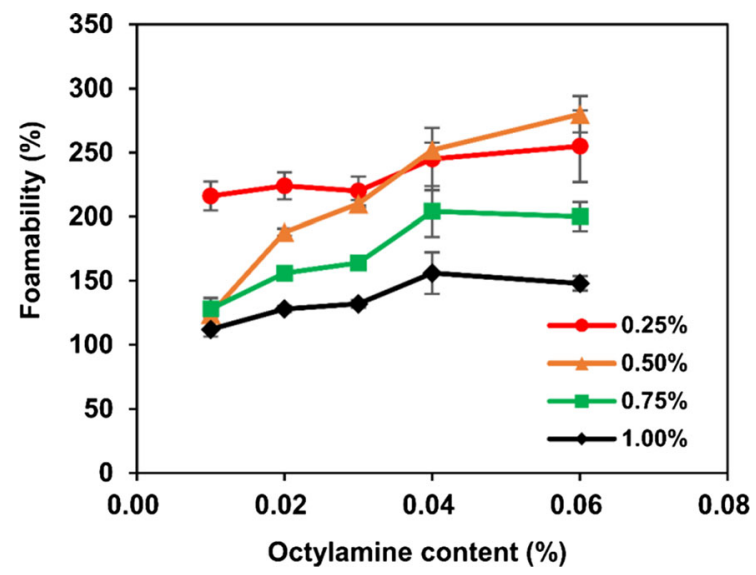

Fig. 1 Foamability of carboxymethylated cellulose nanofibril (CMCNF) wet foam depending on CMCNF consistency and octylamine content (red line: CMCNF $0.25 \mathrm{wt} \%$; orange line: CMCNF $0.5 \mathrm{wt} \%$; green line: CMCNF $0.75 \mathrm{wt} \%$; black line: CMCNF $1.0 \mathrm{wt} \%)$. volume of the wet foam increased sharply with increasing amounts of octylamine. This resulted from the good interaction between the CNF and the surfactant because the amount of CNF was enough to form and stabilize the bubbles. In the case of the high consistency ( $>0.75 \mathrm{wt} \%$ ) CNF suspension, the foamability was similar to that of $0.5 \mathrm{wt} \% \mathrm{CMCNF}$ at 0.01 wt $\%$ surfactant content, but it increased slowly with the increasing amount of surfactant and remained below $200 \%$. This may have resulted from the fact that the viscosity of the CMCNF suspension increased rapidly with increasing consistency: the viscosities of the 0.75 and $1.0 \mathrm{wt} \% \mathrm{CMCNF}$ suspension were 5400 and 15000 cPs, respectively. High viscosity corresponds to low mobility of CNF, and this may have contributed to low levels of foam generation at high consistency of the CNF suspension.

The morphology of the bubbles comprising each wet foam was observed via optical microscopy (Fig. 2). The bubble size decreased with the increasing CNF consistency of the foam when the dosage of the octylamine was less than $0.02 \mathrm{wt} \%$ owing to the decrease in the

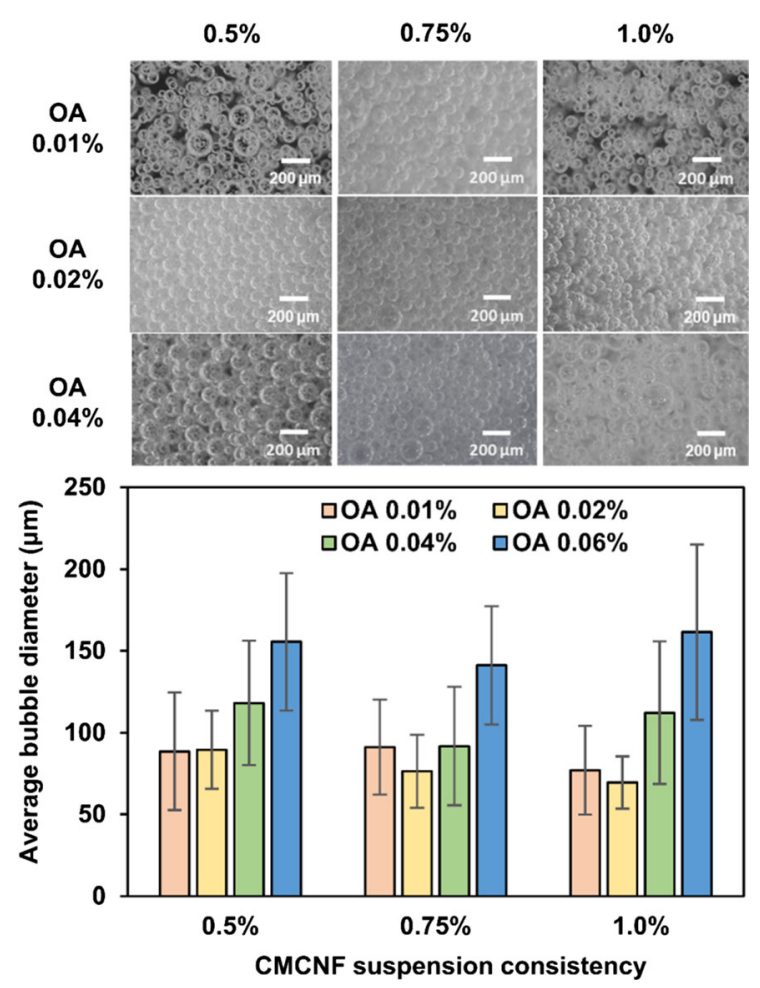

Fig. 2 Microscopic images and average diameters of bubbles in CMCNF wet foam with different CMCNF consistencies and octylamine $(\mathrm{OA})$ contents 
mobility of the suspension. However, the difference in bubble size was not significant at higher octylamine content. In addition, the amount of octylamine also affected the bubble diameter of the foam. Wet foam with $0.01 \mathrm{wt} \%$ octylamine was only partly composed of bubbles, so the volume of liquid between the bubbles was large, demonstrating that the amount of surfactant was not enough for sufficient foam generation. This insufficient foam generation seemed to contribute to the low number of bubbles, with a wider distribution of bubble sizes at 0.5-1.0 wt\% CMCNF consistencies. When the amount of octylamine increased from $0.01 \mathrm{wt} \%$ to $0.02 \mathrm{wt} \%$, the wet foam was completely filled with bubbles, and the size of the bubbles decreased and the uniformity of the bubbles increased owing to the increase in the number of bubbles by a proper interaction between nanofibrils and surfactant. For an octylamine content of $>0.02 \mathrm{wt} \%$, the average size of the bubbles increased and the size distribution of the bubbles widened owing to the generation of bubbles with instability.

The stability of bubbles with different octylamine dosages was evaluated by measuring the time-dependent changes in the average bubble diameter. The average size of the bubbles increased over time, and the size distribution of the bubbles broadened (Fig. 3 and Fig. S1), and correspondingly, the standard deviation of the bubble size increased. This resulted probably from the aging of bubbles through coarsening, coalescence, and Ostwald ripening (Cervin et al. 2013; Fameau and Salonen 2014; Denkov et al. 2020).

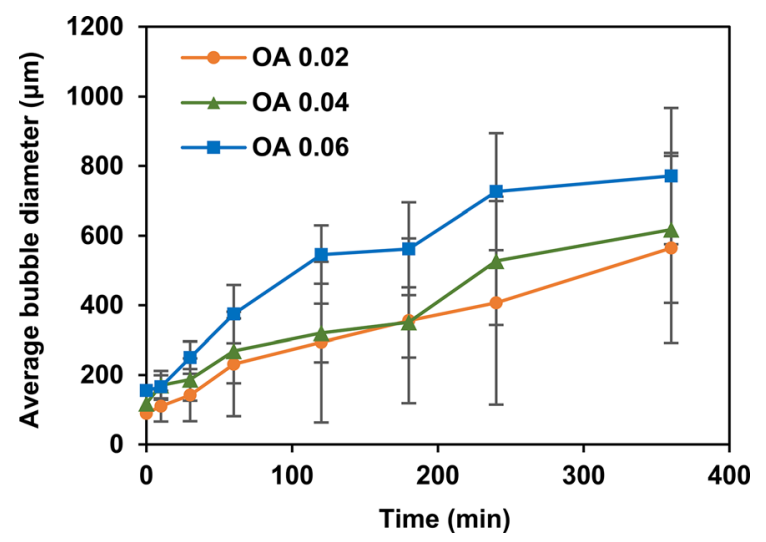

Fig. 3 Time-dependent changes in the average bubble diameter of the wet foam with $0.5 \mathrm{wt} \% \mathrm{CMCNF}$ suspension with 0.02 $\mathrm{wt} \%$ (orange line), $0.04 \mathrm{wt} \%$ (green line), and $0.06 \mathrm{wt} \%$ (blue line) OA content
In fact, the size of the bubbles in the wet foam with higher octylamine concentrations increased more rapidly than that of the bubbles in the foam with lower concentrations; this indicated that a larger amount of the surfactant resulted in faster aging of the bubbles. For example, $0.06 \mathrm{wt} \%$ of octylamine in $0.5 \mathrm{wt} \% \mathrm{CMCNF}$ seemed to be an excessive amount from the viewpoint of wet foam stability since the bubbles grew more rapidly than under other conditions. Previous studies (Cervin et al. 2013, 2015) have reported that an excessive amount of cationic surfactant (more than one-third the surface charge of CNF) deteriorates wet foam stability. The zeta potentials of the CMCNF suspensions with different levels of added octylamine decreased with increasing octylamine (see Fig. S2). This was owing to electrostatic interaction between the anionic $\mathrm{CMCNF}$ and the cationic octylamine. When $4 \mathrm{wt} \%$ octylamine based on the CMCNF weight was added, the surface charge of the CMCNF decreased by one-third, which represented an optimal amount of cationic surfactant according to previous work (Cervin et al. 2013). A dosage of $4 \%$ octylamine corresponds to a $0.02 \mathrm{wt} \%$ dosage in 0.5 $\mathrm{wt} \% \mathrm{CMCNF}$. At this level of addition, the stability of the wet foam was improved. Further addition of the surfactant led to a decrease in the repulsive force between the CNFs, thereby resulting in an aggregation of the fibrils due to interaction between positively charged octylamine and negatively charged CMCNF. Thus, bubbles with excess dosage of the surfactant (1) underwent coarsening, coalescence, or Ostwald ripening more frequently (than those with lower dosages), and (2) this led to a rapid decrease in the stability and increase in the size of the bubbles.

The surfactant-dependent aging behavior of the wet foam could be also explained in terms of the number of fibrils surrounding each bubble as shown in Fig. 4. Low dosage $(0.01 \mathrm{wt} \%$ based on the suspension weight) of the surfactant yielded insufficient levels of foaming, and liquid phases, which remained bubblefree, were observed (Fig. 4a). The optimal dosage of the surfactant $(0.02-0.04 \mathrm{wt} \%)$ generated sufficient and uniform bubbles (Fig. 4b). Compared with the optimal dosage, an excess dosage ( $>0.04$ wt $\%$ ) generated a larger number of bubbles in the wet foam, leading to a decrease in the number of CNFs surrounding each bubble at a given CNF consistency. Thus, the bubbles in the foam with an excess amount of surfactant were expected to be less stable (due to 
(a) Low dosage of surfactant

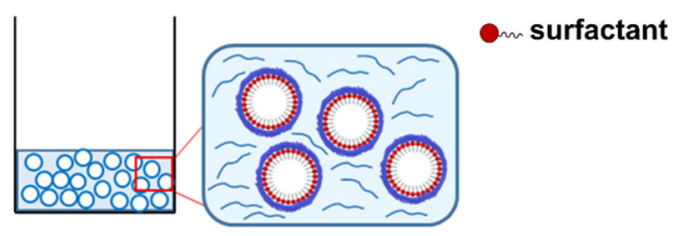

(b) Optimal dosage of surfactant

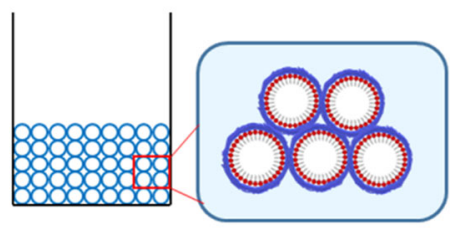

(c) Excess dosage of surfactant

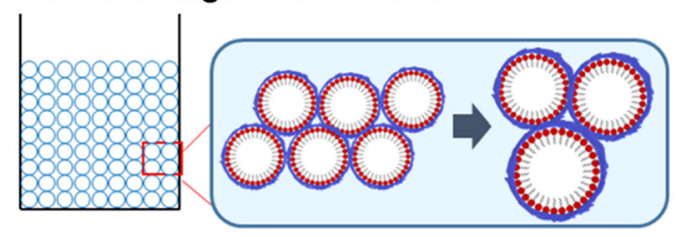

Fig. 4 Schematic showing the surfactant-dependent bubble aging of the CMCNF wet foam, a low dosage, $\mathbf{b}$ optimal dosage, and $\mathbf{c}$ excess dosage. The size differences among the surfactant, $\mathrm{CNF}$, and bubbles were neglected in this figure

their thinner or insufficient amount of CNF layer) than those in the foam with an optimal amount of surfactant. In addition, the charge screening effect of the cationic surfactant also contributed to a decrease in the stability of the bubbles. The consequent coalescence or Ostwald ripening of these unstable bubbles led to larger and less uniform bubble sizes (Fig. 4c) than those of the stable bubbles. These findings indicated that an adequate amount of the surfactant is crucial for the preparation of CNF wet foam with stable bubbles.

The structural stability of the wet foams was observed over a day (Fig. 5). The structure of foams prepared using $0.5-1.0 \mathrm{wt} \%$ suspension was maintained for a week without any drainage of water or destruction of structural features owing to high enough viscosity. However, water drainage occurred within a day for the foam prepared from $0.25 \mathrm{wt} \%$ suspension. Previous studies have reported that, compared with lower consistency (lower viscosity), higher CNF consistency (higher viscosity) resulted in thicker lamellar features around the bubbles and strong entanglements in the foam (Cervin et al. 2015; Huang et al. 2018). This prevented the coalescence and
Ostwald ripening of the bubbles and the drainage of water below the wet foam layer, leading eventually to improved stability of the foam. Based on the results of this study, the expectation was that CMCNF with over $0.5 \mathrm{wt} \%$ consistency or high enough viscosity over $900 \mathrm{cPs}$ was adequate for producing a stable CNF wet foam.

The storage modulus $\left(\mathrm{G}^{\prime}\right)$, loss modulus $\left(\mathrm{G}^{\prime}\right)$, and yield stress of the wet foam were evaluated and their contributions to the network strength were compared (Fig. 6). For all conditions, the storage modulus was higher than the loss modulus at the low stress level, indicating that the wet foam exhibited elastic behavior. $\mathrm{G}^{\prime}$ was maintained until a certain level of stress was reached and decreased thereafter, and the curves of $\mathrm{G}^{\prime}$ and $\mathrm{G}^{\prime \prime}$ intersect near the yield point of the foam. After the crossing point, $G^{\prime \prime}$ was higher than $G^{\prime}$, indicating that the foam behaved like a liquid due to the destruction of bubbles. The yield stress was determined from the intersection point between two tangential lines of the storage modulus. An octylamine content of $0.01 \mathrm{wt} \%$, which was insufficient for foam generation, led to a low storage modulus. However, the storage modulus and the yield stress of the foam increased as the amount of octylamine increased to the optimal level. This suggested that, compared with the wet foam with an inadequate amount of surfactant, the foam with an adequate amount was more stable against the stress. However, increasing the octylamine content further led to reductions in the modulus and stress, owing possibly to a decrease in the stability of bubbles. The rheology of the wet foam was also affected by the CMCNF consistency, i.e., the yield stress increased with increasing consistency, owing to the viscosity of the CMCNF suspension. Consequently, the stability of the wet foam could be estimated by evaluating the rheological property of the foam.

\section{Characteristics of dried CNF foam}

Wet foams were placed in a PTFE dish, and then dried at $60{ }^{\circ} \mathrm{C}$ in a convection oven at a fixed humidity. Under this condition, the structure of stable wet foams was maintained during the drying process, whereas the structure of unstable wet foams was destroyed or large cavities were generated (Figs. 7, 8). When the consistency of the CMCNF suspension was $0.25 \mathrm{wt} \%$, all the bubbles were destroyed during 


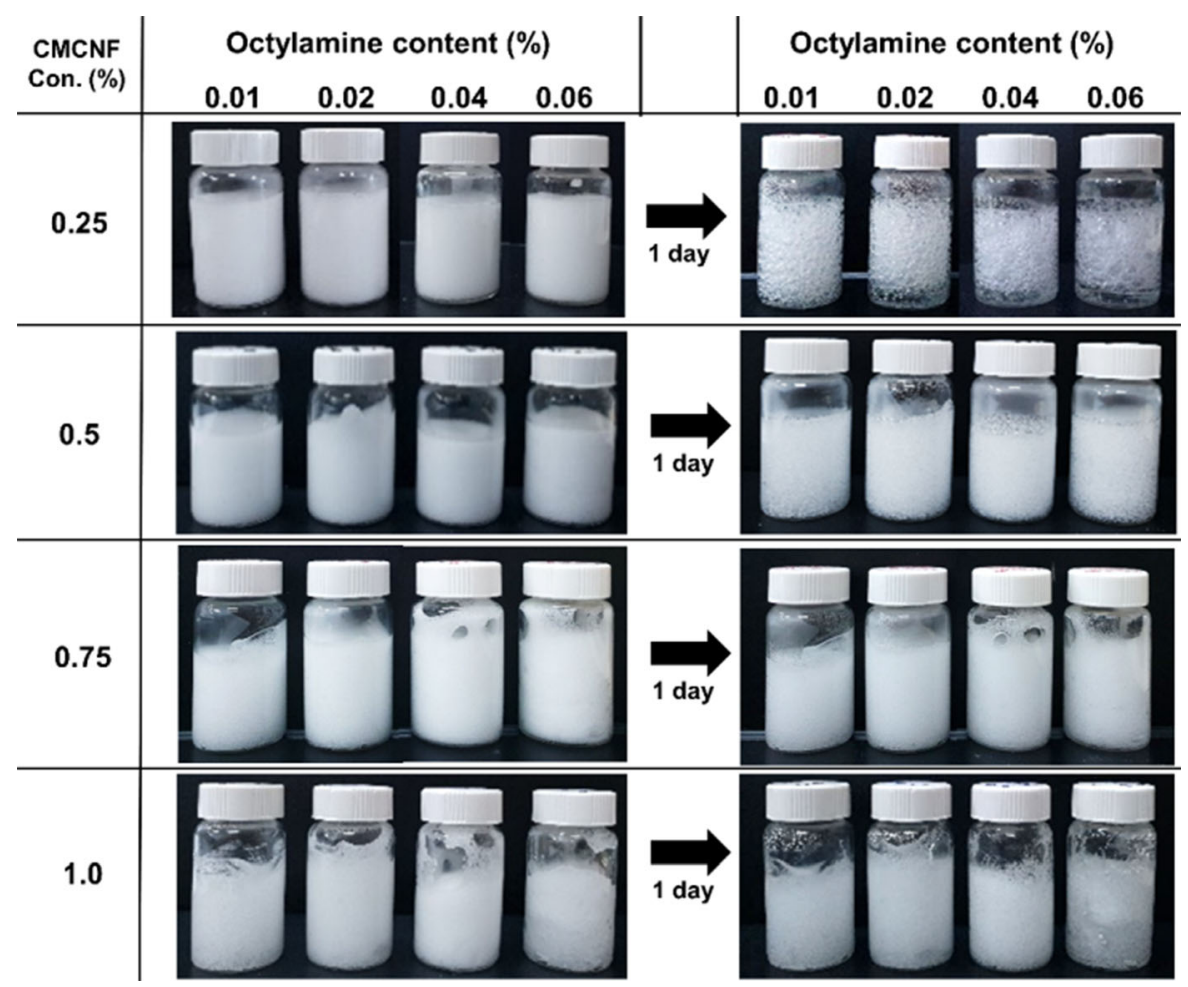

Fig. 5 Stability of CMCNF wet foam immediately after foaming and after 1 day

drying and the foam collapsed due to the poor stability of the wet foam. The structure of foams prepared from 0.5 to $1.0 \mathrm{wt} \%$ consistency suspension was dependent on the CMCNF consistency and the amount of octylamine. Generally, the thickness of the foam decreased with increasing CMCNF consistency (Fig. 8), because the foamability of the wet foam decreased with increasing CNF consistency. The amount of the surfactant also influenced the drying behavior of the foam. We consider the addition of an adequate amount of octylamine $(0.02 \mathrm{wt} \%$ for $0.5 \mathrm{wt} \%$ and $0.75 \mathrm{wt} \% \mathrm{CMCNF}$ suspension and $0.04 \mathrm{wt} \%$ for $1.0 \mathrm{wt} \% \mathrm{CMCNF}$ suspension): with this addition, the foam structure could be maintained without large cavities or severe destruction because the stability of the structure was sufficient to endure the drying stress. Insufficient levels of octylamine addition led to incomplete bubble generation in the suspension, and significant foam shrinkage in the thickness direction, which yielded foam with a small thickness. Octylamine additions greater than the optimal level led to large cavities in the structure or shape deformation of the foam, owing to the large and unstable bubbles in the corresponding wet foam. These unstable bubbles merged with other adjacent bubbles and were destroyed during drying, leading to the formation of cavities or collapse of the structure. Consequently, the stability of wet foam generated at adequate $\mathrm{CNF}$ consistency and octylamine levels was essential for producing oven-dried CNF foam.

The structural properties including the z-directional shrinkage ratio, density, porosity, and average diameter of the pores are presented in Table 1. Most of the dry foams obtained via the oven drying of CMCNF wet foam exhibited $>97 \%$ porosity. The density and porosity of the foam were strongly affected by the foamability of the wet foam (Fig. S3). That is, the density of the dry foam decreased and the porosity of the foam increased with increasing foamability of the wet foam. Compared with low CNF consistency, higher consistency yielded foam with higher density and lower porosity, owing to the lower foamability, smaller pore size, and thicker pore wall. Regarding the amount of octylamine, the porosity of the foam with 0.01 wt $\%$ of surfactant was relatively low. This resulted from the fact that insufficient numbers of 

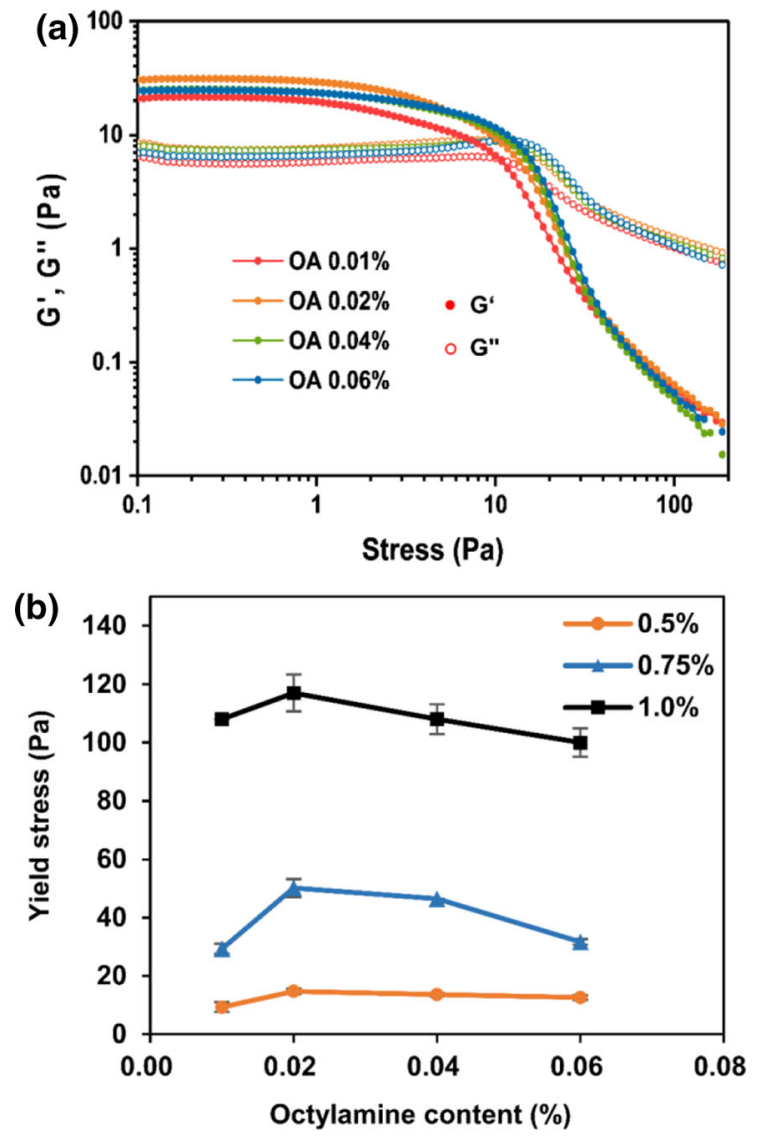

Fig. 6 a Storage modulus $\left(\mathrm{G}^{\prime}\right.$, filled circle) and loss modulus $\left(\mathrm{G}^{\prime \prime}\right.$, open circle) of CMCNF $(0.5 \mathrm{wt} \%)$ wet foam and b yield stress of each CMCNF wet foam (orange line: CMCNF $0.5 \mathrm{wt} \%$; blue line: CMCNF 0.75 wt $\%$; black line: CMCNF $1.0 \mathrm{wt} \%$ )

bubbles were generated when the amount of surfactant was low (foamability was low), thereby leading to significant shrinkage in the thickness direction during drying (Fig. S4). The porosity of the foam increased with increasing amounts of octylamine. The results suggested that (compared with those observed at lower surfactant amounts) the higher foamability and larger bubble size at higher surfactant levels led to an increase in the porosity of the dry foam. In other words, the foamability and the bubble size of the wet foam had a significant effect on the density and porosity of the CNF foam. This indicated that the properties of the dry foam are determined by the consistency of CMCNF and the amount of the surfactant.
The pores of the dried foam were observed from SEM images (Fig. 9). The dry foam was composed of a sphere-like, closed cell structure consistent with the findings of Cervin et al. (2013). However, this structure differed from that of the freeze-dried CNF foam that consisted of directional, small, and open pores (Fig. S5). The average pore diameter (except for large cavities) ranged from 220 to $380 \mu \mathrm{m}$ depending on the foam preparation condition. The pore diameter became larger than that of the bubbles in the wet foam because the bubbles underwent aging during drying.

The average pore size of the foam seemed to be related to the foamability of the wet foam as shown in Fig. S6, which was determined by the consistency of the CMCNF and octylamine dosage. When the CMCNF suspension consistency was low, the average pore diameter tended to be larger than the diameters occurring at high consistency levels. In addition, when the amount of octylamine was insufficient and the foamability of the wet foam was relatively low, the pores became small due to severe shrinkage in the thickness direction during drying. In contrast, the optimal amount of the surfactant improved the foamability of the wet foam, restrained the thicknessdirectional shrinkage, and preserved the pore structure without severe deformation. Hence, these foams were characterized by a relatively bulky and porous structure. Further increase in the concentration of octylamine led to a wide distribution of the pore size due to the presence of cavities or deformation of their structure. Therefore, the porous structure of the oven-dried CNF foam could be controlled by adjusting the preparation conditions of the CNF wet foam, and the foamability of the wet foam which was affected by the suspension consistency and the amount of surfactant played an important role in the process.

The foams prepared in different CMCNF consistencies were subjected to compressive tests and the mechanical properties of each foam were compared with those of the freeze-dried foam (Fig. 10 and Table 2). The compressive stress of the foams increased gradually until a compression strain of $70 \%$ was reached and increased rapidly thereafter, owing to the significant densification of the foams (Gordeyeva et al. 2016). In addition, the stress in the curves obtained for the oven-dried foams slightly decreased at some points, resulting possibly from the 


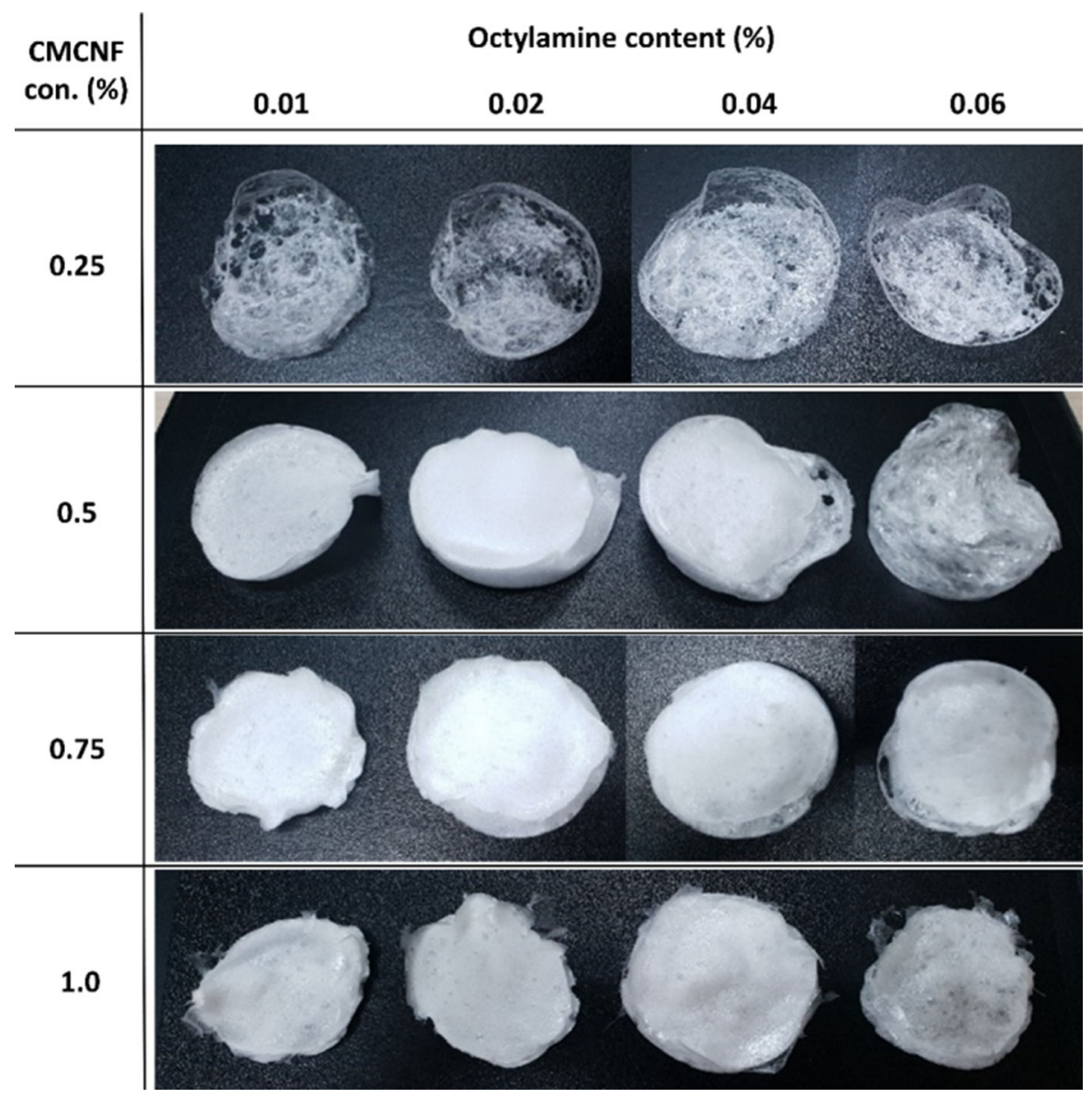

Fig. 7 Dried CMCNF foams prepared at different CNF consistencies and octylamine contents after $60{ }^{\circ} \mathrm{C}$ oven drying

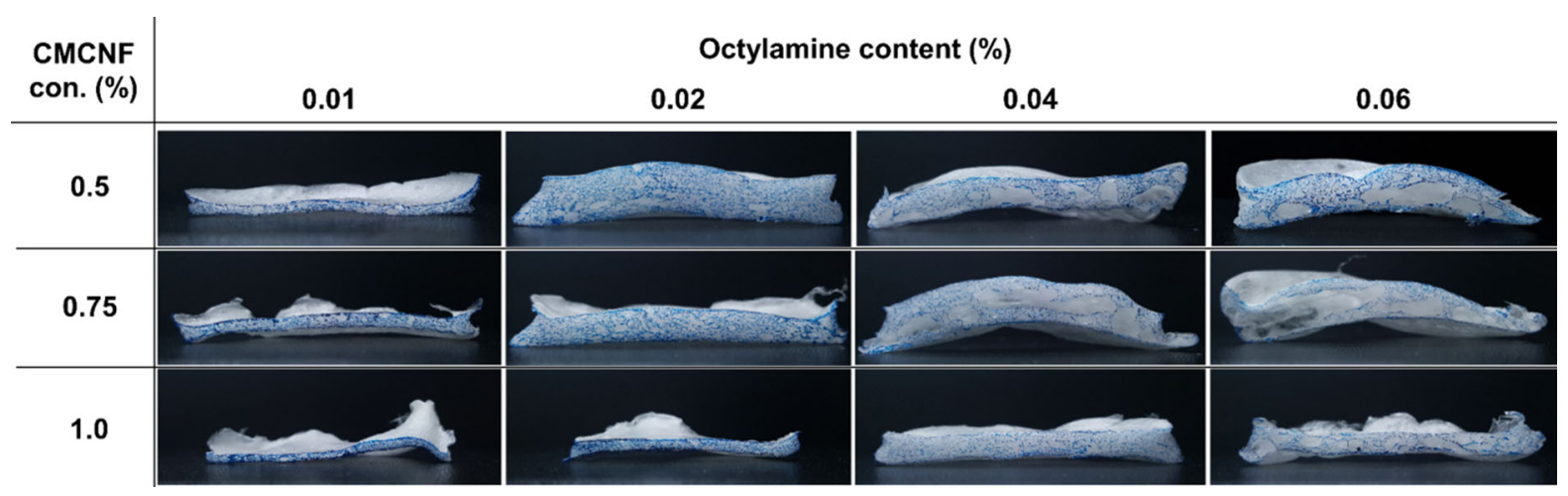

Fig. 8 Cross-sectional images of the dried CMCNF foam with different CMCNF consistencies and octylamine contents. The crosssection of each foam was dyed with blue ink for clear observation 
Table 1 Properties of dried CMCNF foams under different conditions

\begin{tabular}{|c|c|c|c|c|c|c|}
\hline \multirow{2}{*}{$\begin{array}{l}\text { CNF consistency } \\
(\mathrm{wt} \%)\end{array}$} & \multirow{2}{*}{$\begin{array}{l}\text { Octylamine content } \\
(\mathrm{wt} \%)\end{array}$} & \multirow{2}{*}{$\begin{array}{l}\text { Density }{ }^{\mathrm{a}}(\mathrm{kg} / \\
\left.\mathrm{m}^{3}\right)\end{array}$} & \multirow{2}{*}{$\begin{array}{l}\text { Porosity }^{a} \\
(\%)\end{array}$} & \multirow{2}{*}{$\begin{array}{l}\text { Thickness-direction } \\
\text { shrinkage }(\%)\end{array}$} & \multicolumn{2}{|c|}{ Pore diameter $(\mu \mathrm{m})$} \\
\hline & & & & & Average & $\begin{array}{l}\text { Standard } \\
\text { deviation }\end{array}$ \\
\hline \multirow[t]{3}{*}{0.5} & 0.01 & 43 & 97.1 & 84.6 & 246.5 & 118.5 \\
\hline & 0.02 & 9 & 99.4 & 52.2 & 372.4 & 129.5 \\
\hline & 0.04 & $-\mathrm{b}$ & $-{ }^{\mathrm{b}}$ & $-{ }^{\mathrm{b}}$ & 339.0 & 119.3 \\
\hline \multirow[t]{3}{*}{0.75} & 0.01 & 44 & 97.1 & 79.6 & 223.6 & 79.4 \\
\hline & 0.02 & 18 & 98.8 & 63.6 & 298.1 & 91.7 \\
\hline & 0.04 & 16 & 98.9 & 63.5 & 353.6 & 150.8 \\
\hline \multirow[t]{3}{*}{1.0} & 0.01 & 109 & 92.7 & 86.5 & 247.1 & 108.0 \\
\hline & 0.02 & 72 & 95.2 & 81.1 & 236.2 & 63.2 \\
\hline & 0.04 & 20 & 98.7 & 59.4 & 330.2 & 119.3 \\
\hline
\end{tabular}

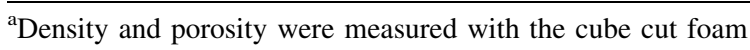

${ }^{\mathrm{b}}$ Deformed structure and large cavities in the foams prevented the determination of these values

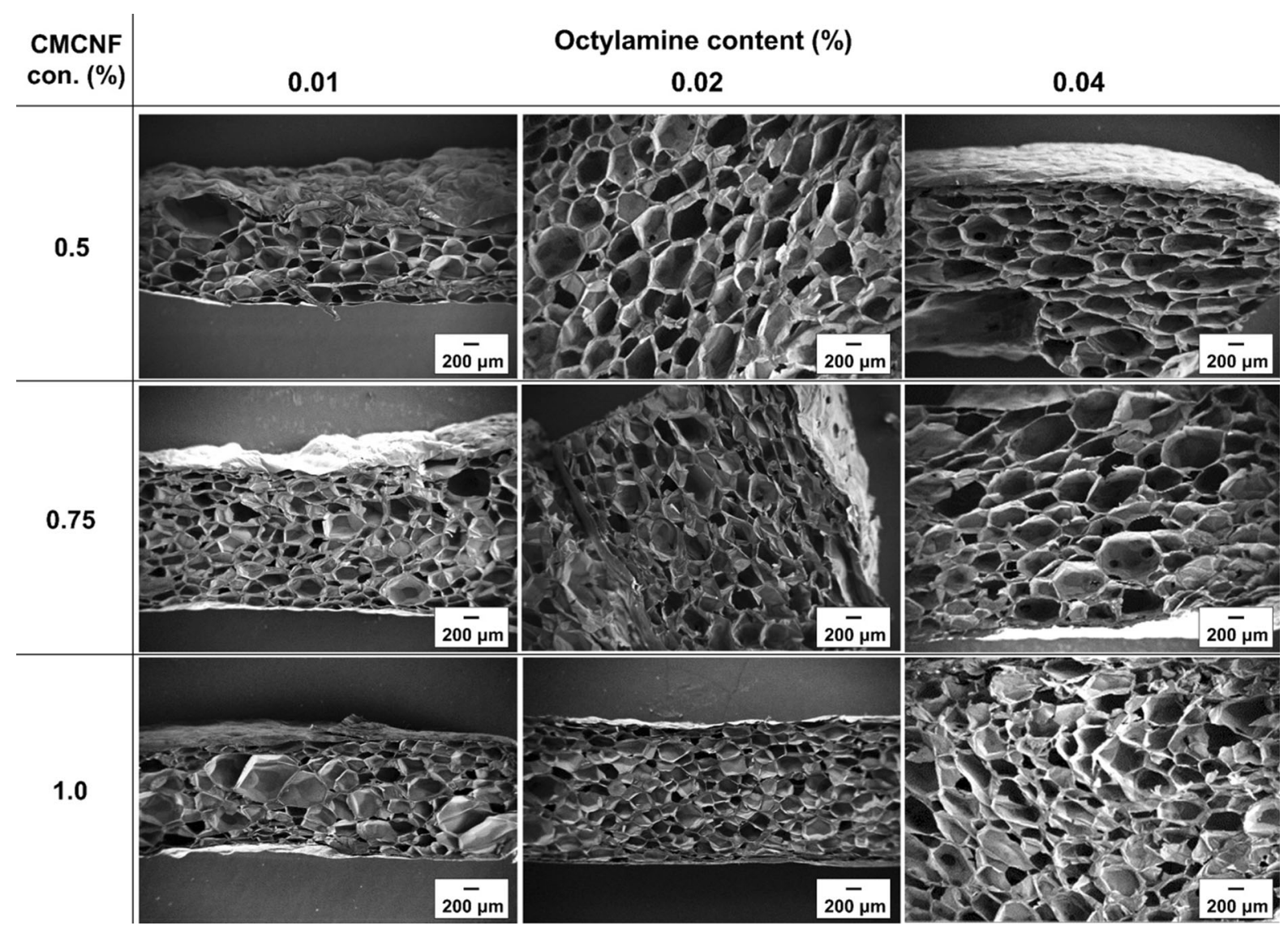

Fig. 9 SEM images showing cross-sections of dried CMCNF foams under different CMCNF consistencies and octylamine contents 


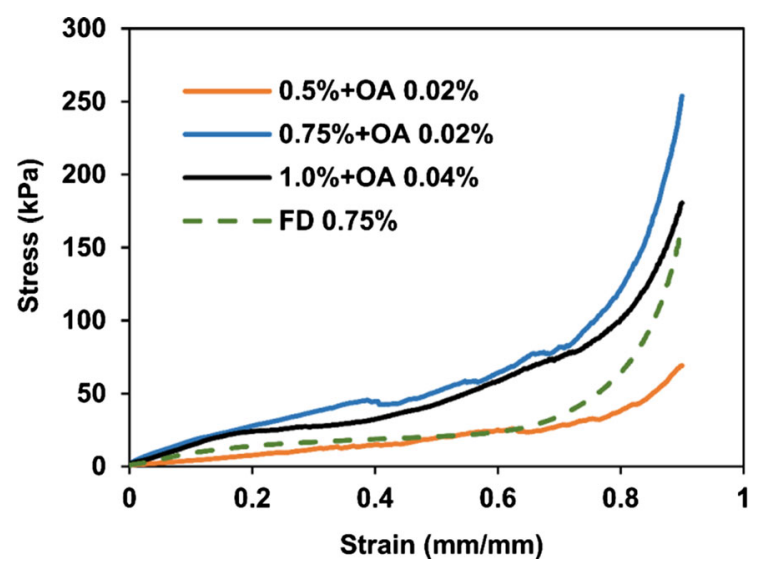

Fig. 10 Stress-strain curves of oven-dried foams and freezedried (FD) foam obtained during compression test (orange line: CMCNF $0.5 \mathrm{wt} \%+\mathrm{OA} 0.02 \mathrm{wt} \%$; blue line: CMCNF 0.75 $\mathrm{wt} \%$ + OA $0.02 \mathrm{wt} \%$; black line: CMCNF $1.0 \mathrm{wt} \%$ + OA 0.04 wt $\%$; green dashed line: freeze dried CMCNF $0.75 \%$ foam)

crushing of closed pores in the foam during compression. The general mechanical properties of the foams are shown in Table 2. The highest compressive strength, Young's modulus, and energy absorption were obtained for the oven-dried foam with $0.75 \mathrm{wt} \%$ CMCNF consistency that had relatively high density $\left(18 \mathrm{~kg} / \mathrm{m}^{3}\right)$ and small pore size $(298.1 \mu \mathrm{m})$. The density of the $1.0 \mathrm{wt} \%$ CMCNF foam with $0.04 \mathrm{wt} \%$ octylamine was similar to that of the $0.75 \mathrm{wt} \%$ CMCNF foam, but the compressive strength was slightly lower owing to the relatively large pore diameters resulting from higher OA dosage. In addition, the compressive strength of the oven-dried CNF foam $(0.75 \mathrm{wt} \%)$ was $83 \%$ higher than that of the freeze-dried foam with the same CMCNF consistency, indicating a greater compression resistance of the oven-dried foam.

\section{Conclusions}

In this study, the effect of CNF suspension consistency and the octylamine content on the properties of CNF wet and oven-dried foams was investigated. The results revealed that these two factors had a significant effect on the foamability and the shape of bubbles. An adequate amount of octylamine, which was $0.02-0.04 \mathrm{wt} \%$ based CNF suspension weight in this study, could generate sufficient and uniform bubbles, maintain sufficient repulsion between fibrils, and led to the production of wet foams with uniform bubbles. The structure of foams obtained from CMCNF suspensions with consistency higher than $0.5 \mathrm{wt} \%$ was maintained for several days, whereas the bubbles of CMCNF with 0.25 wt\% consistency underwent aging. In addition, an optimal amount of octylamine resulted in a high storage modulus, indicating that the stability of the wet foam was determined by both the CMCNF consistency and the surfactant content. When the wet foams were dried in a $60{ }^{\circ} \mathrm{C}$ oven, the porous structure of wet foams with sufficiently high CMCNF consistency and an adequate amount of octylamine was maintained during drying. A CNF foam with a porosity of over $97 \%$ was obtained. The compressive strength of this foam was $83 \%$ higher than that of the freeze-dried foam. An oven-dried CNF foam with a uniform structure was obtained. However, the preparation of a stable CNF wet foam with sufficiently high CNF consistency and an adequate amount of surfactant was essential for producing this foam. Furthermore, the properties of the wet foam seemed to have a significant effect on the properties of the dried CNF foam. This suggested that control of the dry-foam properties

Table 2 Mechanical properties of oven-dried and freeze-dried CMCNF foams

\begin{tabular}{llllll}
\hline $\begin{array}{l}\text { Drying } \\
\text { method }\end{array}$ & $\begin{array}{l}\text { CMCNF consistency } \\
(\mathrm{wt} \%)\end{array}$ & $\begin{array}{l}\text { Octylamine content } \\
(\mathrm{wt} \%)\end{array}$ & $\begin{array}{l}\text { Compressive } \\
\text { strength at } 80 \% \\
\text { strain }(\mathrm{kPa})\end{array}$ & $\begin{array}{l}\text { Young's modulus } \\
(\mathrm{kPa})\end{array}$ & $\begin{array}{l}\text { Energy absorption }(\mathrm{kJ} / \\
\left.\mathrm{m}^{3}\right)\end{array}$ \\
\hline Oven drying & 0.5 & 0.02 & $43.3(4.2)$ & $39.8(5.0)$ & $14.2(1.2)$ \\
& 0.75 & 0.02 & $115.0(11.5)$ & $80.6(22.9)$ & $37.3(3.2)$ \\
& 1.0 & 0.04 & $103.8(14.1)$ & $60.9(5.9)$ & $32.2(1.4)$ \\
$\begin{array}{l}\text { Freeze } \\
\text { drying }\end{array}$ & 0.75 & - & $62.8(2.0)$ & $29.9(10.8)$ & $13.9(3.5)$ \\
\hline
\end{tabular}


can be achieved by adjusting the foaming conditions of the CNF wet foam.

Acknowledgments This work was supported by the National Research Foundation of Korea (NRF) grant funded by the Korea government (MSIT) (No. 2019R1A2C1085476).

\section{Availability of data and materials Not applicable.}

\section{Declarations}

Conflicts of interest The authors declare that there are no conflicts of interest.

Ethical approval All authors state that they adhere to the Ethical Responsibilities of Authors. In addition, this article does not contain any studies with human participants or animals performed by any of the authors.

Open Access This article is licensed under a Creative Commons Attribution 4.0 International License, which permits use, sharing, adaptation, distribution and reproduction in any medium or format, as long as you give appropriate credit to the original author(s) and the source, provide a link to the Creative Commons licence, and indicate if changes were made. The images or other third party material in this article are included in the article's Creative Commons licence, unless indicated otherwise in a credit line to the material. If material is not included in the article's Creative Commons licence and your intended use is not permitted by statutory regulation or exceeds the permitted use, you will need to obtain permission directly from the copyright holder. To view a copy of this licence, visit http://creativecommons.org/licenses/by/4.0/.

\section{References}

Abitbol T, Rivkin A, Cao Y, Nevo Y, Abraham E, Ben-Shalom T, Lapidot S, Shoseyov O (2016) Nanocellulose, a tiny fiber with huge applications. Curr Opin Biotechnol 39:76-88

Binks BP (2002) Particles as surfactants-similarities and differences. Curr Opin Colloid Interface Sci 7:21-41

Bolisetty S, Peydayesh M, Mezzenga R (2019) Sustainable technologies for water purification from heavy metals: review and analysis. Chem Soc Rev 48:463-487

Cervin NT, La A, Ng JBS, Olin P, Bergström L, Wågberg L (2013) Lightweight and strong cellulose materials made from aqueous foams stabilized by nanofibrillated cellulose. Biomacromol 14:503-511

Cervin NT, Johansson E, Benjamins J-W, Wågberg L (2015) Mechanisms behind the stabilizing action of cellulose nanofibrils in wet-stable cellulose foams. Biomacromol $16: 822-831$

Cervin NT, Johansson E, Larsson PA, Wagberg L (2016) Strong, water-durable, and wet-resilient cellulose nanofibril-stabilized foams from oven drying. ACS Appl
Mater Interfaces 8:11682-11689. https://doi.org/10.1021/ acsami.6b00924

Chen C, Ding R, Yang S, Wang J, Chen W, Zong L, Xie J (2020) Development of thermal insulation packaging film based on poly (vinyl alcohol) incorporated with silica aerogel for food packaging application. LWT 109568

Darpentigny C, Nonglaton G, Bras J, Jean B (2020) Highly absorbent cellulose nanofibrils aerogels prepared by supercritical drying. Carbohydr Polym 229:115560

de Oliveira JP, Bruni GP, El Halal SLM, Bertoldi FC, Dias ARG, da Rosa ZE (2019) Cellulose nanocrystals from rice and oat husks and their application in aerogels for food packaging. Int J Biol Macromol 124:175-184

Demilecamps A, Beauger C, Hildenbrand C, Rigacci A, Budtova T (2015) Cellulose-silica aerogels. Carbohyd Polym 122:293-300

Denkov N, Tcholakova S, Politova-Brinkova N (2020) Physicochemical control of foam properties Curr Opin Colloid. Interface Sci 50:101376

Du X, Zhang Z, Liu W, Deng Y (2017) Nanocellulose-based conductive materials and their emerging applications in energy devices-a review. Nano Energy 35:299-320

Dufresne A (2013) Nanocellulose: a new ageless bionanomaterial. Mater Today 16:220-227

Dufresne A (2017) Nanocellulose: from nature to high performance tailored materials. Walter de Gruyter GmbH \& Co $\mathrm{KG}$, Berlin

Fameau A-L, Salonen A (2014) Effect of particles and aggregated structures on the foam stability and aging. C R Phys 15:748-760

Feng J, Nguyen ST, Fan Z, Duong HM (2015) Advanced fabrication and oil absorption properties of super-hydrophobic recycled cellulose aerogels. Chem Eng J 270:168-175

Ghanadpour M, Carosio F, Larsson PT, Wågberg L (2015) Phosphorylated cellulose nanofibrils: a renewable nanomaterial for the preparation of intrinsically flame-retardant materials. Biomacromol 16:3399-3410

Gordeyeva KS, Fall AB, Hall S, Wicklein B, Bergstrom L (2016) Stabilizing nanocellulose-nonionic surfactant composite foams by delayed Ca-induced gelation. J Colloid Interface Sci 472:44-51. https://doi.org/10.1016/j.jcis. 2016.03.031

Guevara JS, Mejia AF, Shuai M, Chang Y-W, Mannan MS, Cheng Z (2013) Stabilization of Pickering foams by highaspect-ratio nano-sheets. Soft Matter 9:1327-1336

Gupta P, Singh B, Agrawal AK, Maji PK (2018) Low density and high strength nanofibrillated cellulose aerogel for thermal insulation application. Mater Des 158:224-236

Hasan MA, Sangashetty R, Esther ACM, Patil SB, Sherikar BN, Dey A (2017) Prospect of thermal insulation by silica aerogel: a brief review. J Inst Eng (india) Ser D 98:297-304

Heath L, Thielemans W (2010) Cellulose nanowhisker aerogels. Green Chem 12:1448-1453

Hong HJ, Lim JS, Hwang JY, Kim M, Jeong HS, Park MS (2018) Carboxymethlyated cellulose nanofibrils(CMCNFs) embedded in polyurethane foam as a modular adsorbent of heavy metal ions. Carbohydr Polym 195:136-142. https://doi.org/10.1016/j.carbpol.2018.04. 081

Huang A, He Y, Zhou Y, Zhou Y, Yang Y, Zhang J, Luo L, Mao Q, Hou D, Yang J (2019) A review of recent applications of 
porous metals and metal oxide in energy storage, sensing and catalysis. J Mater Sci 54:949-973

Huang Y, Yang J, Chen L, Zhang L (2018) Chitin nanofibrils to stabilize long-life pickering foams and their application for lightweight porous materials. ACS Sustain Chem Eng 6:10552-10561. https://doi.org/10.1021/acssuschemeng. $8 \mathrm{~b} 01883$

Illera D, Mesa J, Gomez H, Maury H (2018) Cellulose Aerogels for thermal insulation in buildings: trends and challenges. Coatings 8:345

Im W, Lee S, Abhari AR, Youn HJ, Lee HL (2018) Optimization of carboxymethylation reaction as a pretreatment for production of cellulose nanofibrils. Cellulose 25:3873-3883

Jin H, Nishiyama Y, Wada M, Kuga S (2004) Nanofibrillar cellulose aerogels. Colloids Surf, A 240:63-67

Kim CH, Youn HJ, Lee HL (2015a) Preparation of cross-linked cellulose nanofibril aerogel with water absorbency and shape recovery. Cellulose 22:3715-3724

Kim J-H, Shim BS, Kim HS, Lee Y-J, Min S-K, Jang D, Abas Z, Kim J (2015b) Review of nanocellulose for sustainable future materials. Int J Precis Eng Manuf Green Technol 2:197-213

Köklükaya O, Carosio F, Wågberg L (2017) Superior flameresistant cellulose nanofibril aerogels modified with hybrid layer-by-layer coatings. ACS Appl Mater Interfaces 9:29082-29092

Li J, Zuo K, Wu W, Xu Z, Yi Y, Jing Y, Dai H, Fang G (2018) Shape memory aerogels from nanocellulose and polyethyleneimine as a novel adsorbent for removal of $\mathrm{Cu}$ (II) and $\mathrm{Pb}$ (II). Carbohyd Polym 196:376-384

Liu P, Chen G-F (2014) Porous materials: processing and applications. Elsevier, Amsterdam

Manzocco L, Mikkonen KS, García-González CA (2021) Aerogels as porous structures for food applications: smart ingredients and novel packaging materials. Food Struct 100188

Martoïa F, Cochereau T, Dumont PJ, Orgéas L, Terrien M, Belgacem M (2016) Cellulose nanofibril foams: links between ice-templating conditions, microstructures and mechanical properties. Mater Des 104:376-391
Pääkkö M, Vapaavuori J, Silvennoinen R, Kosonen H, Ankerfors M, Lindström T, Berglund LA, Ikkala O (2008) Long and entangled native cellulose I nanofibers allow flexible aerogels and hierarchically porous templates for functionalities. Soft Matter 4:2492-2499

Pickering SU (1907) Cxcvi.- - emulsions. J Chem Soc Trans 91:2001-2021

Sehaqui H, Salajková M, Zhou Q, Berglund LA (2010) Mechanical performance tailoring of tough ultra-high porosity foams prepared from cellulose I nanofiber suspensions. Soft Matter 6:1824-1832

Singh N, Nagpal G, Agrawal S (2018) Water purification by using adsorbents: a review. Environ Technol Innov 11:187-240

Tenhunen TM, Pohler T, Kokko A, Orelma H, Gane P, Schenker M, Tammelin T (2018) Enhancing the stability of aqueous dispersions and foams comprising cellulose nanofibrils (CNF) with $\mathrm{CaCO}(3)$ particles. Nanomaterials (basel) 8:651. https://doi.org/10.3390/nano8090651

Xhanari K, Syverud K, Stenius P (2011) Emulsions stabilized by microfibrillated cellulose: the effect of hydrophobization, concentration and o/w ratio. J Dispersion Sci Technol 32:447-452

Xiang W, Preisig N, Ketola A, Tardy BL, Bai L, Ketoja JA, Stubenrauch C, Rojas OJ (2019) How cellulose nanofibrils affect bulk, surface, and foam properties of anionic surfactant solutions. Biomacromol 20:4361-4369. https://doi. org/10.1021/acs.biomac.9b01037

Yang Y, Fang Z, Chen X, Zhang W, Xie Y, Chen Y, Liu Z, Yuan W (2017) An overview of Pickering emulsions: solidparticle materials, classification, morphology, and applications. Front Pharmacol 8:287

Zhang N, Zang G-L, Shi C, Yu H-Q, Sheng G-P (2016) A novel adsorbent TEMPO-mediated oxidized cellulose nanofibrils modified with PEI: preparation, characterization, and application for $\mathrm{Cu}$ (II) removal. J Hazard Mater 316:11-18

Publisher's Note Springer Nature remains neutral with regard to jurisdictional claims in published maps and institutional affiliations. 